\title{
Decoupling the response of an estuarine shrimp to architectural components of habitat structure
}

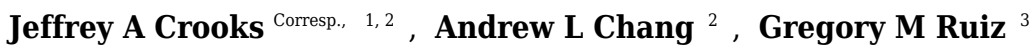 \\ 1 Tijuana River National Estuarine Research Reserve, Imperial Beach, CA, United States \\ 2 Smithsonian Environmental Research Center, Tiburon, California, United States \\ 3 Smithsonian Environmental Research Center, Edgewater, Maryland, United States \\ Corresponding Author: Jeffrey A Crooks \\ Email address: jcrooks@trnerr.org
}

Both the amount and arrangement of structural elements can affect responses to habitat, but it can be difficult to tease the two apart. In order to explore attraction to structure, we examined how the amount and arrangement of artificial stalks affected responses of a shrimp, Palaemon macrodactylus, absent other proximate factors such as predation or interspecific competition. In aquaria, we tested the effect of differing densities of both unbranched and branched stalks, where the amount of material in the branched stalk equaled four-times that of the un-branched. The results clearly showed that it was the amount of material, not how it was arranged, that elicited responses from shrimp. Also, although stalks were not purposefully designed to mimic structural elements found in nature, they did resemble biogenic structure such as hydroids, algae, or plants. In order to test shrimp attraction to a different, perhaps more unfamiliar habitat type, we examined responses to plastic "army men." These structural elements elicited similar attraction of shrimp, and, in general, shrimp response correlated well with the fractal dimension of both stalks and army men. Overall, these results indicate that attraction to physical structure, regardless of its nature, may be an important driver of high abundances often associated with complex habitats. 
1

2

3

4

5

6

7

8

9 1Present Address: Tijuana River National Estuarine Research Reserve, 301 Caspian Way,

10

11

12

13

14

15

16

17

18

19 Correspondence Information: Jeff Crooks, TRNERR, 301 Caspian Way, Imperial Beach, CA, 20
Decoupling the response of an estuarine shrimp to architectural components of habitat structure

Jeffrey A. Crooks ${ }^{1,2}$, Andrew L. Chang ${ }^{2}$, and Gregory M. Ruiz ${ }^{3}$ Imperial Beach, CA, 91932, USA.

${ }^{2}$ Smithsonian Environmental Research Center, Romberg Tiburon Center, 3150 Paradise Drive

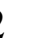
Tiburon, CA 94920, USA.

${ }^{3}$ Smithsonian Environmental Research Center, 647 Contees Wharf Road, Edgewater, Maryland,

4
21037, USA.

USA. Phone: (619) 575 3613, Fax: (619) 575 6913, Email: jcrooks@trnerr.org 


\section{Abstract}

Both the amount and arrangement of structural elements can affect responses to habitat,

23 but it can be difficult to tease the two apart. In order to explore attraction to structure, we

24 examined how the amount and arrangement of artificial stalks affected responses of a shrimp,

25 Palaemon macrodactylus, absent other proximate factors such as predation or interspecific

26 competition. In aquaria, we tested the effect of differing densities of both un-branched and

27 branched stalks, where the amount of material in the branched stalk equaled four-times that of

28 the un-branched. The results clearly showed that it was the amount of material, not how it was

29 arranged, that elicited responses from shrimp. Also, although stalks were not purposefully

30 designed to mimic structural elements found in nature, they did resemble biogenic structure such

31 as hydroids, algae, or plants. In order to test shrimp attraction to a different, perhaps more

32 unfamiliar habitat type, we examined responses to plastic "army men." These structural

33 elements elicited similar attraction of shrimp, and, in general, shrimp response correlated well

34 with the fractal dimension of both stalks and army men. Overall, these results indicate that

35 attraction to physical structure, regardless of its nature, may be an important driver of high

36 abundances often associated with complex habitats.

\section{Introduction}

The physical nature of habitats profoundly shapes resident biotic assemblages. Habitat-

40 species relationships underpin basic ecological dynamics (McCoy and Bell, 1991; Matias et al.,

41 2010; Tokeshi and Arakaki, 2012), and also have implications for ecosystem management,

42 conservation, and restoration (e.g., Crooks, 2002; Jimenéz and Conover 2001; Thrush and

43 Dayton, 2002; Byers et al, 2006; St. Pierre and Kovalenko, 2014, Loke et al. 2014). Despite (or 
44 perhaps because of) the ubiquity and importance of habitat-species interactions, there are

45 considerable conceptual and terminological issues associated with even the most fundamental

46 aspects of habitat structure (Matias et al., 2007; Tokeshi and Arakaki, 2012; Kovalenko et al.

47 2013, Loke et al. 2014). In general terms, however, habitat structure is typically considered to be

48 related to two elements: the presence of distinct structural types - habitat heterogeneity; and the

49 absolute abundance and configuration of structural material - structural complexity (Heck and

50 Wetstone 1977; McCoy and Bell, 1991; Sebens, 1991; Beck, 2000). Although this basic

51 framework provides a foundation for considering how the physical nature of habitats shapes

52 communities, these two elements are often confounded in studies examining biotic responses to

53 habitats, making it difficult to quantify the effects of either (Beck, 2000; Matias et al., 2007).

54 The lack of clarity related to habitat structure notwithstanding, numerous studies have

55 demonstrated that "complex" (sensu lato) habitats tend to have more individuals and/or species

56 than less complex habitats, a pattern that has been observed across various systems and at

57 various spatial scales (e.g., Krecker, 1939; MacArthur and MacArthur, 1961; Recher, 1969;

58 Orth, 1973; Dean and Connell, 1987; Crooks, 2002; Thomaz et al., 2008). Complex habitats can

59 serve as predation refuges (Crowder and Cooper, 1982; Everett and Ruiz, 1993; Warfe and

60 Barmuta, 2004), and ameliorate competition (Sale, 1975). The structure of habitats can interact

61 with physical conditions such as wind or currents, modulating the supply of resources such as

62 food (Gutiérrez et al., 2011) or altering the distribution of materials to which species might

63 respond (e.g., olfactory cues, Ferner et al., 2009). Structural complexity may increase living

64 space, especially for relatively small organisms, and the fractal dimension of habitats has been

65 found to correlate positively with density and negatively with body size (Gunnarsson, 1992;

66 Morse et al., 1995; McAbendroth et al., 2005). Increased densities and diversities within 
67 complex habitats also can be caused by net inward fluxes of individuals. In aquatic systems,

68 planktonic larvae can act as largely passive particles, and settlement rates in habitats such as

69 seagrass beds may be increased due to decreased water velocities (Fonseca et al., 1982).

70 Active behavioral choice is also a proximate mechanism for motile species, and given

71 that behavior can mediate individual-ecosystem interactions, behavioral studies are emerging as

72 a key way to explore responses to human-induced environmental change, including impacts of

73 "novel" habitats (Wright et al. 2010; Sih et al., 2011). In aquatic systems, attraction to objects -

74 any object, regardless of whether it is natural or artificial - is a well-known response of a variety

75 of fish and motile invertebrates (Mortensen, 1917; Carlisle et al., 1964; Salazar, 1973; Druce and

76 Kingsford, 1995; Ingólfsson, 1998; Castro et al., 2002). Further, architectural complexity can

77 play a role in determining magnitude of responses (Dean and Connell, 1987; Hacker and

78 Steneck, 1990). A variety of lab and field experiments have examined behavioral responses to

79 the structural complexity of habitats (e.g., Bell and Westoby, 1986; Jeffries, 1993; Gee and

80 Warwick, 1994; Roberston and Weis, 2007). Habitat selection is often evaluated in the presence

81 of predation pressure, either by design or as a consequence of field settings (Crowder and

82 Cooper, 1982; Everett and Ruiz, 1993). Fewer studies have looked at habitat choice in the

83 absence of factors such as predation pressure or food supply, but those that have indicate that the

84 physical arrangement of materials alone can play an important role in shaping the distribution

85 and abundance of motile organisms (Stoner 1980; Bell and Westoby 1986; Hacker and Steneck

86 1990).

87 In this study, we examined attraction to the amount and arrangement of structural

88 elements by a motile organism, the shrimp Palaemon macrodactylus. This grass shrimp is native

89 to Asia, but has been introduced worldwide (Micu and Nita 2009). It was first reported in San 
90 Francisco Bay the 1950's (Newman 1963), and is now one of the most common nektonic

91 organism in the brackish waters there (Hatfield 1985, Crooks pers obs.). Like many motile

92 macrofauna, this shrimp is often found associated with structure, with Newman (1963) noting

93 that it was "frequently found in old tires, tin cans and other artificial structures as well as on

94 pilings, walls and among rocks or calcareous tubes of Mercierella" (Mercierella = Ficopomatus

95 enigmaticus, a non-native, "reef-creating" polychaete worm).

96 The goal of our work was to examine how the complexity and density of structural

97 elements would drive behavioral responses of $P$. macrodactylus, while controlling for other

98 proximate factors which might drive shrimp response (e.g., immediate predation risk and

99 presence of food). This consisted of two experiments, one where shrimp could choose between

100 arrays of structural elements in different configurations, and the other where we examined the

101 response to a single array to assess the degree to which habitat complexity, as assessed with total

102 surface area and fractal dimension, could account for position of shrimp in experimental tanks.

103 The structural elements used in the experiments were plastic mesh cut into different

104 configurations. While these artificial structures were not deliberately constructed to resemble

105 any particular species, they did resemble various organisms in benthic communities (Fig. 1A),

106 such as macroalgae, vascular plants, or hydroids. Other researchers have used similar "mimics"

107 to examine responses of aquatic fauna (e.g., Schneider and Mann, 1991; Jeffries 1993; Bourget

108 and Harvey 1998). In order to determine how shrimp would respond to perhaps more unfamiliar

109 structural forms, we also created two "non-mimic" treatments, consisting of plastic "army men"

110 (toy soldiers and equipment; Fig. 1B).

111

112 


\section{$113 \quad$ 2.1 Methods}

\section{2.1 Location}

115 Asian grass shrimp Palaemon macrodactylus were collected from a floating dock at

116 Black Point, where the Petaluma River enters north-western San Francisco Bay. The shrimp

117 were abundant and easily collected with dip nets, and were transported to the greenhouse facility

118 at Romberg Tiburon Center (San Francisco State University), where they were kept in holding

119 tanks and fed daily with flake fish food. Average-sized shrimp, approx. $4 \mathrm{~cm}$ in length, were

120 selected for use in the experiments, and individual shrimp were used only once (Underwood et

121 al. 2004).

122

1232.2 Experimental Setup

124 All experiments were conducted in 10-gallon aquaria (bottom dimensions $=50.8 \mathrm{~cm} \mathrm{x}$

$12525.4 \mathrm{~cm})$ with a thin $(1-2 \mathrm{~cm})$ layer of sand covering the bottom. The $12 \mathrm{~cm}$-long stalks were cut 126 in two configurations from 1-mm diameter black plastic mesh with approximately $15 \times 15-\mathrm{mm}$

127 openings. Two levels of architectural complexity were used (Figs. 1A and 2). The un-branched

128 stalk was a single strip of mesh with all side branches removed. The branched stalk was cut out

129 of the mesh in such a way that crosspieces were left intact and one branched stalk had the same

130 amount of material and surface area as four un-branched stalks. Two, four, eight, sixteen, and

131 thirty-two stalk configurations were used to assess shrimp responses to structure. Structural

132 material was arrayed uniformly on the $14 \mathrm{x}$ 14-cm PVC plates and fixed in place with hot melt

133 glue. The two non-stalk treatments were created using arrays of toy plastic army men and army

134 equipment (Fig. 1B). These treatments offered different structural types, with less resemblance 
135 to naturally-occurring biogenic structure. There were 8 army men per plate, and 4 pieces of

136 army equipment.

137 Panels were placed on the bottom of the tank with the surfaces buried so that only the

138 stalks or toys were visible above the sand. The test area was the surface immediately above the

139 entire $14 \times$ 14-cm panel (Fig. 2). All tanks were kept within in a blackout tent to control light

140 exposure, with illumination provided by overhead fluorescent lamps set on a timer with $12 \mathrm{~h}$

141 light / dark cycles. Individual tanks were wrapped on all vertical sides with opaque black plastic

142 to prevent reflections and reactions to shrimp in neighboring tanks.

143 At the beginning of each trial run, five shrimp were placed in each tank and left to

144 acclimate overnight. The next morning, observations were taken every half hour for 6 hours, for

145 a total of 13 observations. Observations were taken by lifting the opaque plastic cover from one

146 long vertical side of each tank and counting the number of shrimp in the test area. Testing before

147 the experiment identified this as the best method for observing shrimp without startling them,

148 and during the course of the experiment we did not notice shrimp respond to our observations.

149 This set-up was used in two experiments.

150

1512.3 Choice Between Two Arrays

152 This experiment assessed shrimp responses when presented with structural arrays of

153 varying architectural complexity on opposite sides of the tanks. Two $14 \mathrm{x}$ 14-cm structural

154 arrays (the test areas) were present in each tank, one on each side, which were randomly chosen

155 (Fig. 2). The shrimp were offered four different pairings. There were two choices between

156 arrays of equal stalk density: 8 un-branched vs. 8 branched, or 32 un-branched vs. 32 branched.

157 There were also two choices with equal surface area of material: 2 branched vs. 8 un-branched, 
158 or 8 branched vs. 32 un-branched. The response variable was the average number of shrimp in

159 the each $14 \times 14-\mathrm{cm}$ test area over the course of a trial run. The experiment was a Randomized

160 Complete Block Design, blocked in time and with tanks with each treatment pairing running

161 simultaneously. This was repeated 10 times, with a re-randomization of treatment allocation to

162 tank each time.

163

1642.3 Response to a Single Array

165 This experiment examined shrimp responses to the presence of a single structural array of 166 varying architectural complexity on one randomly-chosen side of each tank, with nothing on the

167 other side. Treatments consisted of 5 densities of un-branched stalks and 5 densities of branched

168 stalks. The response variable was the average number of shrimp in the single $14 \times 14-\mathrm{cm}$ test

169 area over the course of a trial run. The experiment was again blocked in time, with 8 blocks and

170 a re-randomization of treatment allocation to tank each time. Also, the two non-stalk treatments

171 (plastic army men and army equipment) were included in each block.

172

1732.5 Analyses

174 All shrimp density data were log-transformed prior to analysis, and a constant of 0.077

175 was added to all values. This represents the smallest non-zero number that could be obtained

176 (e.g., Warton and Hui, 2009): one shrimp in one test area during one observation period. In the

177 Choice Between Arrays experiment, each pairing was analyzed separately using paired t-tests.

178 For the Response to a Single Array experiment, the effects of stalk density, type, and block were

179 analyzed as a three-factor ANOVA without replication. Comparisons between arrays of equal

180 surface area were conducted using paired t-tests. 
182 five total) were compared to what would be expected if shrimp were randomly distributed on the 183 tank floor using a t-test (i.e., an average of 0.69 shrimp would be expected in the $14 \times 14-\mathrm{cm}$ test 184 area, which constitutes $13.8 \%$ of the total tank bottom). Number of shrimp in the test area was 185 also plotted against fractal dimension of each array type, including the toys. This was done using

186 the program Fractal Dimension Calculator (http://paulbourke.net/fractals/fracdim/), which uses

187 the box-counting method as an estimate of fractal dimension (Morse et al. 1985, Jeffries 1993).

188 In this procedure, a grid is superimposed upon a digitized image and the number of cells

189 occupied by the image is calculated iteratively for progressively smaller cell sizes. Images for

190 this analysis were taken from the sides of three replicate arrays for each array type. In order to

191 assess if shrimp responded to the toys similarly as the stalks, we determined the degree to which

192 individual points affected the relationship between fractal dimension and number of shrimp using

193 Cook's D (Fox, 1991). A cutoff for “influential” points of 4 / (n - k -1) was used (Fox, 1991),

194 where $\mathrm{n}=12$ (number of observations) and $\mathrm{k}=1$ (number of independent variables), resulting in 195 a value of 0.40 .

\section{3. Results}

\subsection{Choice Between Two Arrays} In the case where shrimp in a single tank had a choice between two arrays with differing

200 structural arrangements, the total amount of material, and not how it was arranged, was the

201 primary driver of shrimp response (Fig. 3). In tanks with test areas with equal amounts of

202 material but differing stalk density, no statistically significant differences in number of shrimp

203 were found $(\mathrm{P} \geq 0.39)$. At equal stalk density, however, shrimp preferred test areas with branched 
204 stalks, choosing areas with more structure over those with less (Fig. 3). This effect was

205 particularly apparent at the highest stalk densities, with over 8 times as many shrimp found with

206 branched stalks than with un-branched $(\mathrm{P}<0.001)$.

207

208

209

\subsection{Response to a Single Array}

210

When presented with a single array per tank, the quantity of structure again had marked

211 effects on shrimp location within tanks (Fig. 4). Both stalk density and stalk type (branched vs.

212 un-branched) were statistically significant. For both stalk types, number of shrimp increased

213 approximately $500 \%$ from the lowest to the highest stalk densities. However, there were no

214 significant differences in shrimp densities in test areas with equal amounts of material but

215 differing stalk density (Fig. 4 - dashed lines), as also observed in the choice experiment (Fig. 3).

216 In general, total stalk surface area, irrespective of stalk type, was an excellent predictor of

217 number of shrimp within the test area (Fig. 5)

218 The shrimp also displayed marked responses to the non-stalk habitat treatments. The

219 army men treatment had a mean density of $2.3( \pm 0.2)$ shrimp per $14 \times 14-\mathrm{cm}$ test area, and the

220 army equipment treatment had a mean density of $1.6( \pm 0.4)$. Both of these are significantly

221 different than what would be expected if shrimp were randomly distributed on the tank bottom

222 (army men: $\mathrm{t}_{7}=11.5, \mathrm{p}<0.001$; army equipment: $\mathrm{t}_{7}=3.22, \mathrm{p}=0.015$ ). Also, these shrimp

223 densities are comparable to the two highest values found using branched stalk treatments.

224 Fractal dimension, as assessed with the box-counting method, was again an excellent

225 predictor of number of shrimp within the test area (Fig. 6). Although stalks and toys represent

226 quite different structural forms (as well as textures and colors), fractal dimension accounted for 
$22793 \%$ of the variability to shrimp number $\left(\mathrm{R}^{2}=0.93, \mathrm{P}<0.001\right)$. The values for Cook's $\mathrm{D}$, which

228 assesses outliers (or "influential points") in regressions, all fell below the cut-off of 0.4 (although

229 the value for the army equipment approached this at $\mathrm{D}=0.37$ ). Also, for the stalk treatments, it

230 is important to note that the amount of material was also very closely related to the fractal

231 dimension of the arrays (logarithmic regression, $\mathrm{R}^{2}=0.98, \mathrm{P}<0.001$ ).

232

233 4. Discussion

234 These experiments demonstrate that shrimp responded to the presence of structure in the

235 absence of proximate factors such as predation pressure and food supply, and that an excellent

236 predictor of shrimp location was the amount of material available. These findings support

237 previous suggestions that surface area tends to be a good measure of complexity (Stoner, 1980;

238 Stoner and Lewis, 1985; Beck, 2000). For example, Attrill et al. (2000) found that macro-

239 invertebrate community structure in seagrass beds was associated with the amount of plant

240 available, and Dean and Connell (1987) showed that intertidal invertebrates chose algal clumps

241 of based on biomass rather than species identity. Not surprisingly, however, exceptions to this

242 relationship are found, and morphologically different structures with constant surface areas have

243 been shown to elicit differing responses (Loke and Todd 2016), such as artificial macrophyte

244 beds with many thin blades having higher fish abundance than beds with fewer, thicker blades

245 (Jenkins and Sutherland, 1997). In other cases, surface area might underestimate the number of

246 individuals and species found within increasingly complex habitats (Hauser et al. 2006), or,

247 conversely, there might be negative relationships between amount of material and invertebrate

248 communities (Kelahar 2003). Together, these emphasize that other processes are at work beyond 
249 just surface area, and it is necessary to consider factors such as scale and environmental context

250 (Kovalenko et al. 2013; Matias 2013).

251 Fractal dimension also was a powerful predictor of shrimp response. Although it is

252 possible that shrimp were also responding to differing cues (such as material or color), fractal

253 dimension explained much of the variability in shrimp response to the two stalk types as well as

254 army toys (Fig. 6). Like other experiments that explicitly attempted comparisons of fractal

255 dimension and surface area (Beck 2000 and references therein), our results have similarly

256 resulted in a limited ability to recommend one over the other given that surface area and fractal

257 dimension were correlated. It is worth noting, though, that fractal dimension, assessed with the

258 box-counting method, is easier to assess than surface area for irregular structures (Beck 2000),

259 but can be difficult to apply in the context of applied conservation or restoration activities (Loke

260 et al. 2014). Although several studies have shown that fractal surfaces offer more usable space

261 for smaller organisms than larger ones, producing a positive relationship between abundance and

262 complexity (Morse et al., 1985; Shorrocks et al. 1991), this argument does not apply here as the

263 shrimp were all comparably-sized (approximately 4-cm).

264 Our results also agree with other studies indicating that behavioral choice is an important

265 factor shaping the distribution and abundance of motile organisms (e.g., Stoner, 1980; Rooke,

266 1984; Bell and Westoby, 1986). In the laboratory setting of these experiments, shrimp were

267 attracted to branched and un-branched structures that generally resembled materials such as

268 hydroids, algae, or plants. In addition, the shrimp responded to forms that might be less typical

269 of natural systems, the plastic army toys. Together, these responses suggest that for these shrimp

270 choice is largely based on the presence of structure of any sort, and not just a response to familiar

271 forms. 
Despite the potentially strong effect of choice on patterns of distribution and abundance,

273 more work is needed on underlying mechanisms, including habitat choice in response to specific

274 behaviors being displayed, such as mating, navigation, feeding, or predator escape (Shumway,

275 2008; Kovalenko et al. 2013; Roever et al., 2014). Many inter-related factors could potentially

276 drive attraction to structure, including thigmotactic movement oriented by contact or touch

277 (Olyslager and Williams, 1993; Uryu et al., 1996; Webster and Laland 2011), or structure

278 offering a visual reference point for activities such as breeding or feeding (e.g., Dagorn and

279 Fréon, 1999). For some organisms, such as birds and mammals, it has been suggested that

280 psychological factors, such as aversion or attraction to novel conditions, serve to structure

281 behaviors and distributional patterns (Greenberg, 1984). Also, although predators were not

282 immediately involved in our experiments, there is likely recognition that complex habitats may

283 afford escape from predation (Bell and Westoby, 1986, Shumway, 2008), and species might alter

284 behavior according to the perceived protective value of habitats even in the absence of

285 immediate predation risk (Ingrum et al., 2010).

286 The response of species to the physical nature of habitats, and the general tendency to

287 choose more complex over simpler structures, has a number of implications for applied ecology.

288 For example, a better understanding of the behavioral responses to structure can improve design

289 of artificial reefs (Gratwicke and Speight, 2005; Perkol-Finkel et al., 2006) and fish aggregating

290 devices (Dagorn and Fréon, 1999; Castro et al., 2001, Girard et al., 2004). The generality of

291 behavioral responses to structure also allows prediction of the effects of habitat-modifying exotic

292 species, as invasive ecosystem engineers may create unfamiliar, novel habitat types that tend to

293 benefit at least some resident biota regardless of the exact type of structure being created

294 (Crooks, 2002). Clearly, there will be exceptions to the pattern of positive relationships between 
295 complexity and species responses (Crooks, 2002, Gutiérrez and Iribarne, 2004). For example,

296 complex habitats can impair visual fields (Rilov et al., 2007) or interfere with foraging, such as

297 the invasive alga Caulerpa interfering with feeding of native mullet (Levi and Francour, 2004).

298 Given the potential importance of the recognition and response of organisms to habitat

299 complexity, more research is needed on this subject (Shumway, 2008). In general, it will be

300 valuable to examine habitat preferences in the absence of other extrinsic factors in a wide range

301 of species, as understanding such interspecific differences may help explain community-level

302 patterns (e.g., Greenberg 1984). For P. macrodactylus, which has been shown to demonstrate a

303 high degree of correlation between habitat complexity and magnitude of response (this study), it

304 would be interesting to determine whether responses are innate rather than learned (which might

305 be accomplished by examining lab-reared versus field-caught individuals), as well as to conduct

306 experiments with varying densities of conspecifics in order to determine the potential role of

307 density-dependent, intraspecific interactions in shaping distribution. It also would be valuable to

308 compare results of artificial structures to natural ones, including carefully-controlled field

309 experiments to explore shrimp responses in the presence of other factors that would affect

310 distribution in natural settings (Underwood et al. 2004).

311

\section{Conclusions}

313 The results of these and other experiments demonstrate that attraction to physical

314 structure in the absence of proximate mechanisms such as food supply and predators can explain

315 patterns of increased densities within complex habitats. However, it is clear that the habitat

316 structure affects resident biota in many other fundamental ways, including active and passive

317 accumulation of individuals (Fonseca et al., 1982), amelioration of competition (Sale, 1975) and 
318 environmental conditions (Bruno and Bertness, 2001), and predator avoidance (Everett and Ruiz,

319 1993). As many of these factors will tend to promote higher densities within complex habitats, it

320 can be difficult to tease out the relative importance of each when all are potentially operating.

321 Nevertheless, it is likely this synergism that drives attraction to complex structure.

322

323 Acknowledgements

324 We thank the staff at the Romberg Tiburon Center, San Francisco State University, for helping to 325 facilitate this work.

\section{References}

329 Attrill, M.J., Strong, J.A., and Rowden, A.A. (2000). Are macroinvertebrate communities

330 influenced by seagrass structural complexity? Ecography 23, 114-121.

331 Beck, M., 2000. Separating the elements of habitat structure: independent effects of habitat complexity and structural components on rocky intertidal gastropods. J. Exp. Mar. Biol. Ecol. 249, 29-49.

334 Bell, J.D., Westoby, M., 1986. Abundance of macrofauna in dense seagrass is due to habitat preference, not predation. Oecologia 68, 205-209.

Bourget, E. and Harvey, M., 1998. Spatial analysis of recruitment of marine invertebrates on arborescent substrata. Biofouling, 12, 45-55.

Bruno, J.F., Bertness, M.D. 2001. Habitat modification and facilitation in benthic marine communities, in: Bertness, M.D., Gaines, S.D., Hay, M.E. (Eds.) Marine Community

340 Ecology, Sinauer Associates, Inc, Massachusetts, pp. 201-218. 
341 Byers, J.E., Cuddington, K., Jones, C.G., Talley, T.S., Hastings, A., Lambrinos, J.G., Crooks,

342 J.A., Wilson, W.G., 2006. Using ecosystem engineers to restore ecological systems. Trends

343 Ecol. Evol. 21, 493-500.

344 Carlisle, J.G. Jr., Turner, C.H., Ebert, E.E., 1964. Artificial habitat in the marine environment.

345 California Department of Fish and Game, Fish Bulletin 124.

346 Castro, J.J., Santiago, J.A., Santana-Ortega, A.T., 2001. A general theory on fish aggregation to

347 floating objects: An alternative to the meeting point hypothesis. Rev. Fish. Biol. Fisheries

$348 \quad 11,255-277$.

349 Crooks, J.A., 2002. Characterizing ecosystem-level consequences of biological invasions: the

$350 \quad$ role of ecosystem engineers. Oikos $97,153-166$.

351 Crowder, L.B., Cooper, W.E., 1982. Habitat structural complexity and the interaction between 352 bluegills and their prey. Ecology 63, 1802-1813.

353 Dagorn, L., Fréon, P., 1999. Tropical tuna associated with floating objects: a simulation study of 354 the meeting point hypothesis. Can. J. Fish. Aquat. Sci. 56, 984-993.

355 Dean, R.L., Connell, J.H., 1987. Marine invertebrates in an algal succession. III. Mechanisms

356 linking habitat complexity with diversity. J. Exp. Mar. Biol. Ecol. 109, 249-273.

357 Druce, B.E. and Kingsford, M.J. 1995. An experimental investigation on the fishes associated 358 with drifting objects in coastal waters of temperate Australia. Bulletin of Marine Science, 57: $359 \quad 378-392$.

360 Everett, R.A., Ruiz, G.M., 1993. Coarse woody debris as a refuge from predation in aquatic 361 communities. An experimental test. Oecologia 93, 475-486.

362 Ferner, M., Smee, D., Weissburg, M., 2009. Habitat complexity alters lethal and non-lethal 363 olfactory interactions between predators and prey. Mar. Ecol. Prog. Ser. 374, 13-22. 
364 Fonseca, M.S., Fisher, J.S., Zieman, J.C., Thayer, G.W., 1982. Influence of the seagrass, Zostera

365 marina L., on current flow. Estuar. Coast. Shelf S. 15, 351-364.

366 Fox, J. 1991. Regression Diagnostics. SAGE Publications, Inc, Thousand Oaks, California, USA.

367 Gee, J.M., Warwick, R.M., 1994. Metazoan community structure in relation to the fractal

368 dimensions of marine macroalgae. Mar. Ecol. Prog. Ser. 103, 141-150.

369 Girard, C., Benhamou, S., Dagorn, L., 2004. FAD: Fish Aggregating Device or Fish Attracting

370 Device? A new analysis of yellowfin tuna movements around floating objects. Anim. Behav.

$371 \quad 67,319-326$.

372 Gratwicke, B., Speight, M.R., 2005. The relationship between fish species richness, abundance

373 and habitat complexity in a range of shallow tropical marine habitats. Journal of Fish

374 Biology 66, 650-667.

375 Greenberg, R., 1984. Neophobia in the foraging-site selection of a neotropical migrant bird: an

376 experimental study. P. Natl. Acad. Sci. USA 81, 3778-3780.

377 Gunnarsson, B., 1992. Fractal dimension of plants and body size distribution in spiders.

$378 \quad$ Functional Ecology 6: 636-641.

379 Gutiérrez, J., Iribarne, O., 2004. Conditional responses of organisms to habitat structure: an

380 example from intertidal mudflats. Oecologia 139, 572-582.

381 Gutiérrez, J.L., Jones, C.G., Byers, J.E., Arkema, K.K., Berkenbusch, K., Commito, J.A., Duarte,

382 C.M., Hacker, S.D., Lambrinos, J.G., Hendriks, I.E., Hogarth, P.J., Palomo, M.G., Wild, C.,

383 2011. Physical ecosystem engineers and the functioning of estuaries and coasts, in:

384 Wolanski, E., McLusky, D.S. (Eds.) Treatise on Estuarine and Coastal Science, Vol 7.

385 Academic Press, Waltham, Massachusetts, pp. 53-81. 
386 Hacker, S.D. and Steneck, R.S. 1990. Habitat architecture and the abundance and body-size-

387 dependent habitat selection of a phytal amphipod. Ecology 71: 2269-2285.

388 Hauser, A., Attrill, M.J., Cotton, P.A., 2006. Effects of habitat complexity on the diversity and 389 abundance of macrofauna colonising artificial kelp holdfasts. Mar. Ecol. Prog. Ser. 325, 93$390 \quad 100$.

391 Heck, K.L., Wetstone, G.S., 1977. Habitat complexity and invertebrate species richness and 392 abundance in tropical seagrass meadows. J. Biogeogr. 4, 135.

393 Ingølfsson, A. 1998. Dynamics of macrofaunal communities of floating seaweed clumps off 394 western Iceland: a study of patches on the surface of the sea. Journal of Experimental 395 Marine Biology and Ecology 231: 119-137.

396

397 398 399 400 401 402 403 404 405 406 407 408

Ingrum, J., Nordell, S.E., Dole, J., 2010. Effects of habitat complexity and group size on perceived predation risk in goldfish (Carassius auratus). Ethol. Ecol. Evol. 22, 119-132.

Jeffries, M., 1993. Invertebrate colonization of artificial pondweeds of differing fractal dimension. Oikos 67, 142-148.

Jenkins, G.P., Sutherland, C.R., 1997. The influence of habitat structure on nearshore fish assemblages in a southern Australian embayment: colonisation and turnover rate of fishes associated with artificial macrophyte beds of varying physical structure. J. Exp. Mar. Biol. Ecol. 218, 103-125.

Jenkins, G., Walker-Smith, G., Hamer, P., 2002. Elements of habitat complexity that influence harpacticoid copepods associated with seagrass beds in a temperate bay. Oecologia 131, $598-605$.

Jiménez, J.E., Conover, M.R., 2001. Ecological approaches to reduce predation on groundnesting gamebirds and their nests. Wildlife Soc. B. 29, 62-69. 
409 Kelaher, B.P., 2003. Changes in habitat complexity negatively affect diverse gastropod

$410 \quad$ assemblages in coralline algal turf. Oecologia 135, 431-441.

411 Kovalenko, K.E., Thomaz, S.M., Warfe, D.M., 2011. Habitat complexity: approaches and future 412 directions. Hydrobiologia 685, 1-17.

413 Krecker, F.H., 1939. A comparative study of the animal population of certain submerged aquatic 414 plants. Ecol. 20, 553-562.

415 Levi, F., Francour, P., 2004. Behavioural response of Mullus surmuletus to habitat modification 416 by the invasive macroalga Caulerpa taxifolia. J. Fish Biol. 64, 55-64.

417 Loke, L.H.L., Jachowski, N.R., Bouma, T.J., Ladle, R.J. \& Todd, P.A., 2014. Complexity for 418 Artificial Substrates (CASU): Software for creating and visualising habitat complexity. PLoS 419 ONE 9, e87990.

420 Loke, L.H.L., Todd, P.A., 2106. Structural complexity and component type increase intertidal 421 biodiversity independently of area. Ecology 97, 383-393.

422 MacArthur, R.H., MacArthur, J.W., 1961. On bird species diversity Ecol. 42, 594-598.

423 Matias, M.G., 2013. Macrofaunal responses to structural complexity are mediated by 424 environmental variability and surrounding habitats. Mar. Biol. 160, 493-502.

425 Matias, M.G., Underwood, A.J., Coleman, R.A., 2007. Interactions of components of habitats 426 alter composition and variability of assemblages. J. Anim. Ecol. 76, 986-994.

427 Matias, M.G., Underwood, A.J., Hochuli, D.F., Coleman, R.A., 2010. Independent effects of 428 patch size and structural complexity on diversity of benthic macroinvertebrates. Ecol. 91, $429 \quad 1908-1915$. 
430 McAbendroth, L., Ramsay, P.M., Foggo, A., Rundle, S.D., Bilton, D.T., 2005. Does macrophyte 431 fractal complexity drive invertebrate diversity, biomass and body size distributions? Oikos $432 \quad 111,279-290$.

433 McCoy, E.D., Bell, S.S., 1991. Habitat structure: the evolution and diversification of a complex 434 topic, in: Bell, S.S., McCoy, E.D., Mushinsky, H.R. (Eds.), Habitat structure: the physical 435 arrangement of objects in space. Chapman and Hall, London, pp. 3-21.

436 Morse, D.R., Lawton, J.H., Dodson, M.M., Williamson, M.H., 1985. Fractal dimension of 437 vegetation and the distribution of arthropod body lengths. Nature 314, 731-733.

438 Mortensen, T., 1917. Observations on protective adaptation and habits, mainly in marine 439 animals, in: Papers from Dr. Th. Mortensen’s Pacific Expedition 1914-1916. Vidensk. 440 Medd. Dansk Naturhist. Forem. 69, pp. 57-96.

441 Newman, W.A. 1963. On the introduction of an edible oriental shrimp (Caridea, Palaemonidae) 442 to San Francisco Bay. Crustaceana 5:119-132.

443 Olyslager, N.J., Williams, D.D., 1993. Microhabitat selection by the lotic amphipod Gammarus 444 pseudolimnaeus Bousfield: mechanisms for evaluating local substrate and current suitability. 445 Canadian Journal of Zoology 71, 2401-2409.

446 Orth, R.J., 1973. Benthic infauna of eelgrass,Zostera marina, beds. Chesapeake Science 14, 258$447 \quad 269$.

448 Perkol-Finkel, S., Shashar, N., Benayahu, Y., 2006. Can artificial reefs mimic natural reef 449 communities? The roles of structural features and age. Mar. Environ. Res. 61, 121-135. 450 Recher, H.F., 1969. Bird species diversity and habitat diversity in Australia and North America. 451 Am. Nat. 103: 75-80. 
452 Rilov, G., Figueira, W.F., Lyman, S.J., Crowder, L.B., 2007. Complex habitats may not always 453 benefit prey: linking visual field with reef fish behavior and distribution. Mar. Ecol. Prog. 454 Ser. $329,225-238$.

455 Robertson, T.L., Weis, J.S., 2007. Interactions between the grass shrimp Palaemonetes pugio and 456 the salt marsh grasses Phragmites australis and Spartina alterniflora. Biol. Invasions 9, 25457 30.

Roever, C.L., Beyer, H.L., Chase, M.J., van Aarde, R.J., 2014. The pitfalls of ignoring behaviour when quantifying habitat selection. Divers. Distrib. 20, 322-333.

Rooke, J.B., 1984. The invertebrate fauna of four macrophytes in a lotic system Freshwater Biol. 14, 507-513.

Salazar, M.H., 1973. Animal attraction to sunken submarines. Oceans 6: 68-70.

Sale, P.F., 1975. Patterns of use of space in a guild of territorial reef fishes. Mar. Biol. 29, 89-97.

Schneider, F.I., Mann, K.H., 1991. Species specific relationships of invertebrates to vegetation in a seagrass bed. I. Experiments on the importance of macrophyte shape, epiphyte cover and predation. Journal of Experimental Marine Biology and Ecology, 145, 119-139.

Sebens, K.P., 1991. Habitat structure and community dynamics in marine benthic systems, in: the distribution of arthropod body lengths. Funct. Ecol. 5, 457-460.

Shumway, C.A., 2008. Habitat complexity, brain, and behavior. Brain Behav. Evol. 72, 123-134. 
475 St Pierre, J.I., Kovalenko, K.E., 2014. Effect of habitat complexity attributes on species richness. $476 \quad$ Ecosphere 5, art22.

477 Stoner, A.W., 1980. The role of seagrass biomass in the organization of benthic macrofaunal $478 \quad$ assemblages. B. Mar. Sci. 30, 537-551.

479 Stoner, A.W., Lewis, F.G.I., 1985. The influence of quantitative and qualitative aspects of 480 habitat complexity in tropical seagrass meadows. J. Exp. Mar. Biol. Ecol. 94, 19-40.

481 Thomaz, S.M., Dibble, E.D., Evangelista, L.R., Higuti, J., Bini, L.M., 2008. Influence of aquatic 482 macrophyte habitat complexity on invertebrate abundance and richness in tropical lagoons. $483 \quad$ Freshwater Biology 53, 358-367.

484 Thrush, S.F., Dayton, P.K., 2002. Disturbance to marine benthic habitats by trawling and 485 dredging: Implications for marine biodiversity. Annu. Rev. Ecol. Syst. 33, 449-473.

486 Tokeshi, M., Arakaki, S., 2012. Habitat complexity in aquatic systems: fractals and beyond. $487 \quad$ Hydrobiologia 685, 27-47.

488 Underwood, A.J., Chapman, M.G., Crowe, T.P., 2004. Identifying and understanding ecological 489 preferences for habitat or prey. Journal of Experimental Marine Biology and Ecology 300, $490 \quad 161-187$.

491 Uryu, Y., Iwasaki, K., Hinoue, M., 1996. Laboratory experiments on behaviour and movement 492 of a freshwater mussel, Limnoperna fortunei (Dunker). J. Molluscan Studies 62, 327-341. 493 Warfe, D., Barmuta, L., 2004. Habitat structural complexity mediates the foraging success of 494 multiple predator species. Oecologia 141, 171-178.

495 Warton, D.I., Hui, F.K.C., 2011. The arcsine is asinine: the analysis of proportions in ecology. $496 \quad$ Ecology 92:3-10. 
497 Webster, M.M., Laland, K.N., 2011. Reproductive state affects reliance on public information in 498 sticklebacks. P. Roy. Soc. B.-Biol. Sci. 278, 619-627.

499 Wright, J.T., Byers, J.E., Koukoumaftsis, L.P., Ralph, P.J., Gribben, P.E., 2010. Native species

500 behaviour mitigates the impact of habitat-forming invasive seaweed. Oecologia 163, 527$501 \quad 534$. 
Table 1. ANOVA table for the Choice experiment, examining the average number of shrimp in the test areas with differing combinations of stalk density and type.

\begin{tabular}{lcccc} 
Source of Variation & df & MS & F & P-value \\
\hline Density (n=5) & 4 & 1.37 & 12.2 & $<0.001$ \\
Stalk Type: Unbranched vs. Branched (n=2) & 1 & 2.75 & 24.4 & $<0.001$ \\
Block (n=8) & 7 & 0.21 & 1.9 & 0.11 \\
Block * Density & 28 & 0.06 & 0.5 & 0.95 \\
Block* Stalk Type & 7 & 0.26 & 0.2 & 0.98 \\
Density * Stalk Type & 4 & 0.08 & 0.7 & 0.60 \\
Residual & 28 & 0.11 &
\end{tabular}


Figure 1. Examples of experimental treatments. A) Unbranched and branched stalks, showing a configuration with equal surface area. B) The novel, "non-mimic" habitat - plastic army men and equipment.
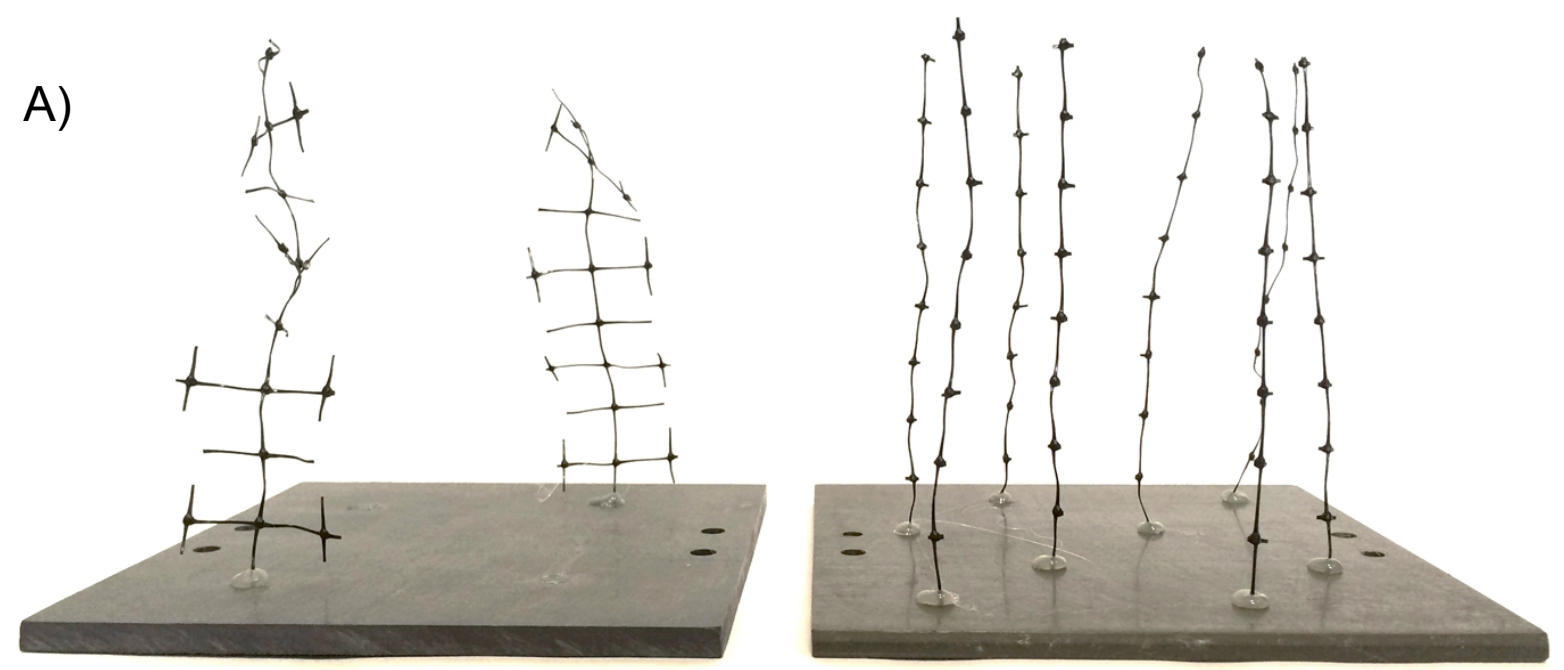

B)
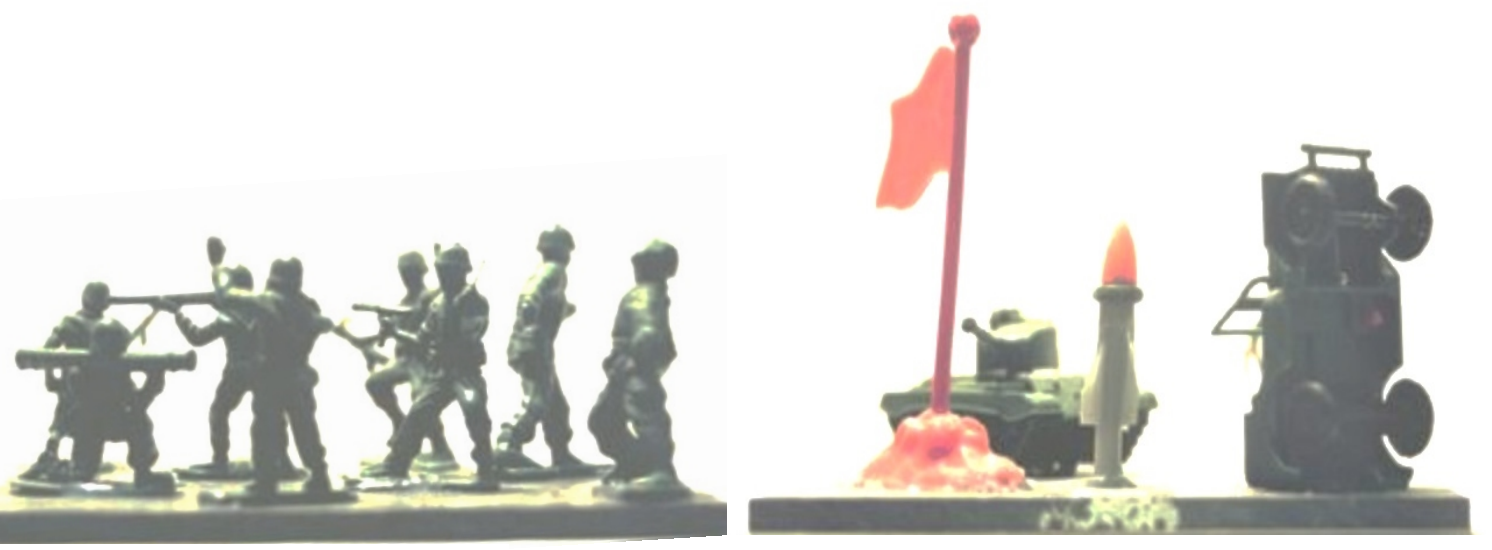
Figure 2. The experimental design. Stalks were constructed so that four un-branched stalks had the same surface area as one branched stalk. Two experiments were run, one where shrimp could choose between structural arrays on opposite sides of the tank, and one where shrimp responded to a single structural array on a randomly-selected side.

Stalk Arrays

(per $14 \times 14 \mathrm{~cm}$ test area)

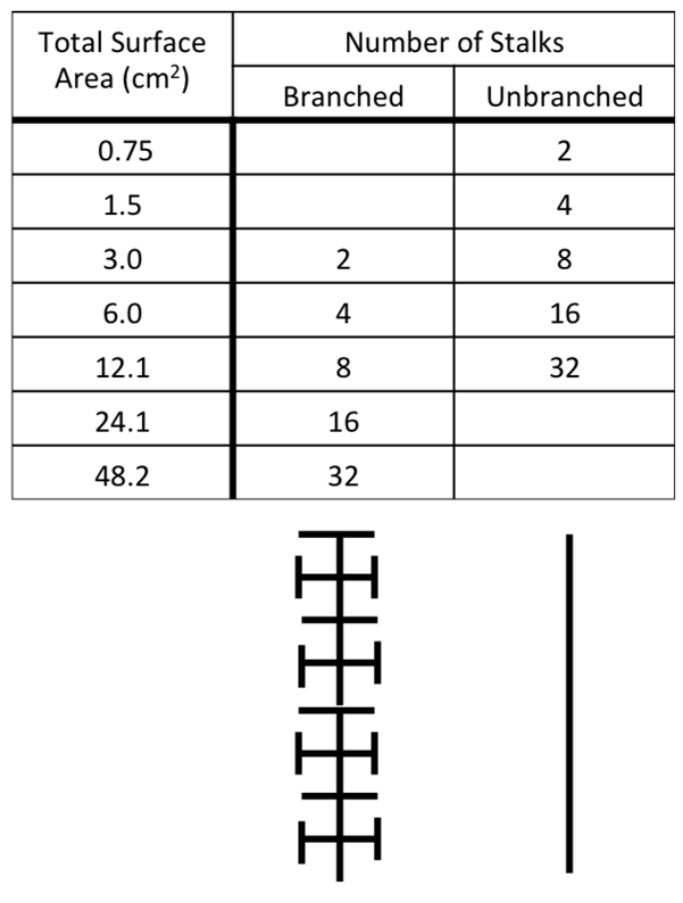

\section{Experimental Set-Up}

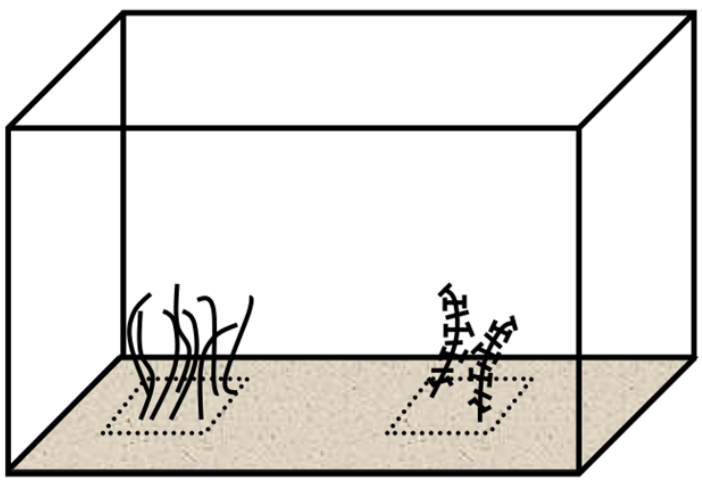

Choice Between Arrays

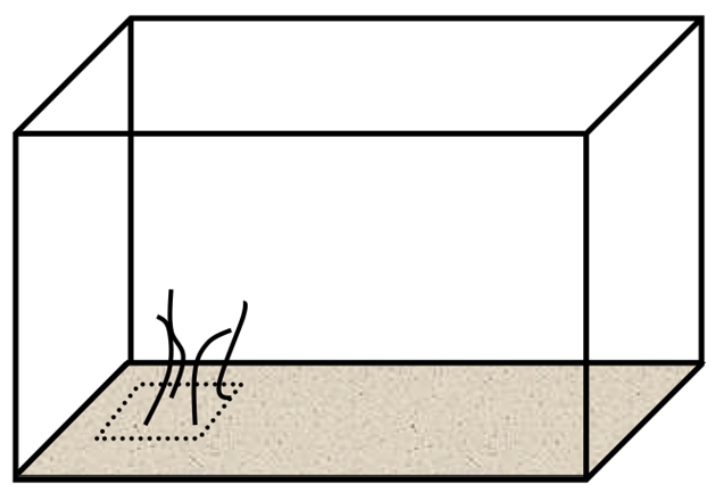

Response to Single Array 
508 Figure 3. Shrimp responses when given a choice between structural arrays with the same surface 509 area or same stalk density.

510

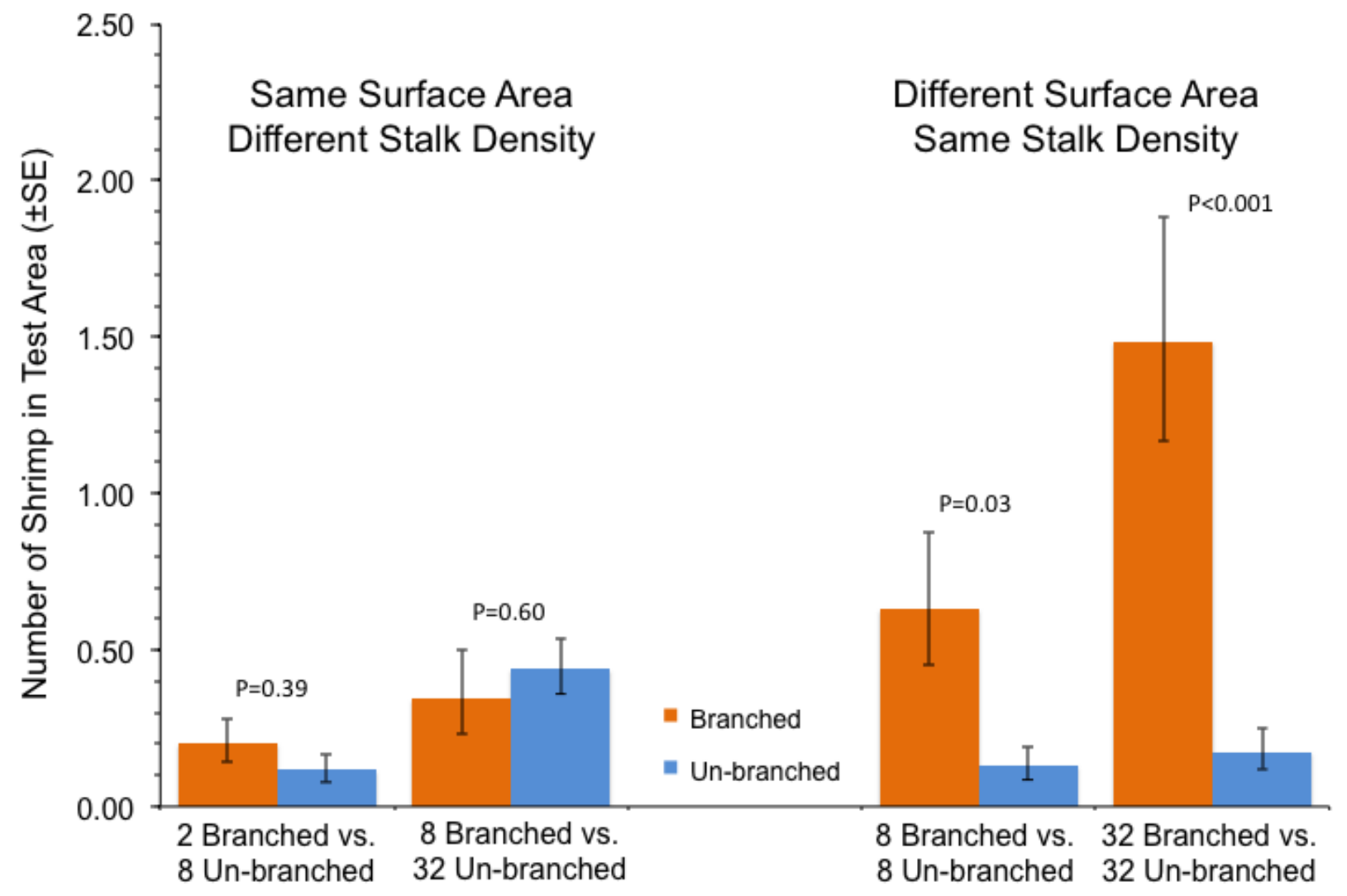


Figure 4. Relationship between number of stalks and number of shrimp in the test area in the tanks with a single array. Also shown with dashed lines are the comparisons between arrays with equal stalk surface area, which were all statistically non-significant (paired t-tests, 7 df, Pvalues $>0.34)$. See also Table 1 .

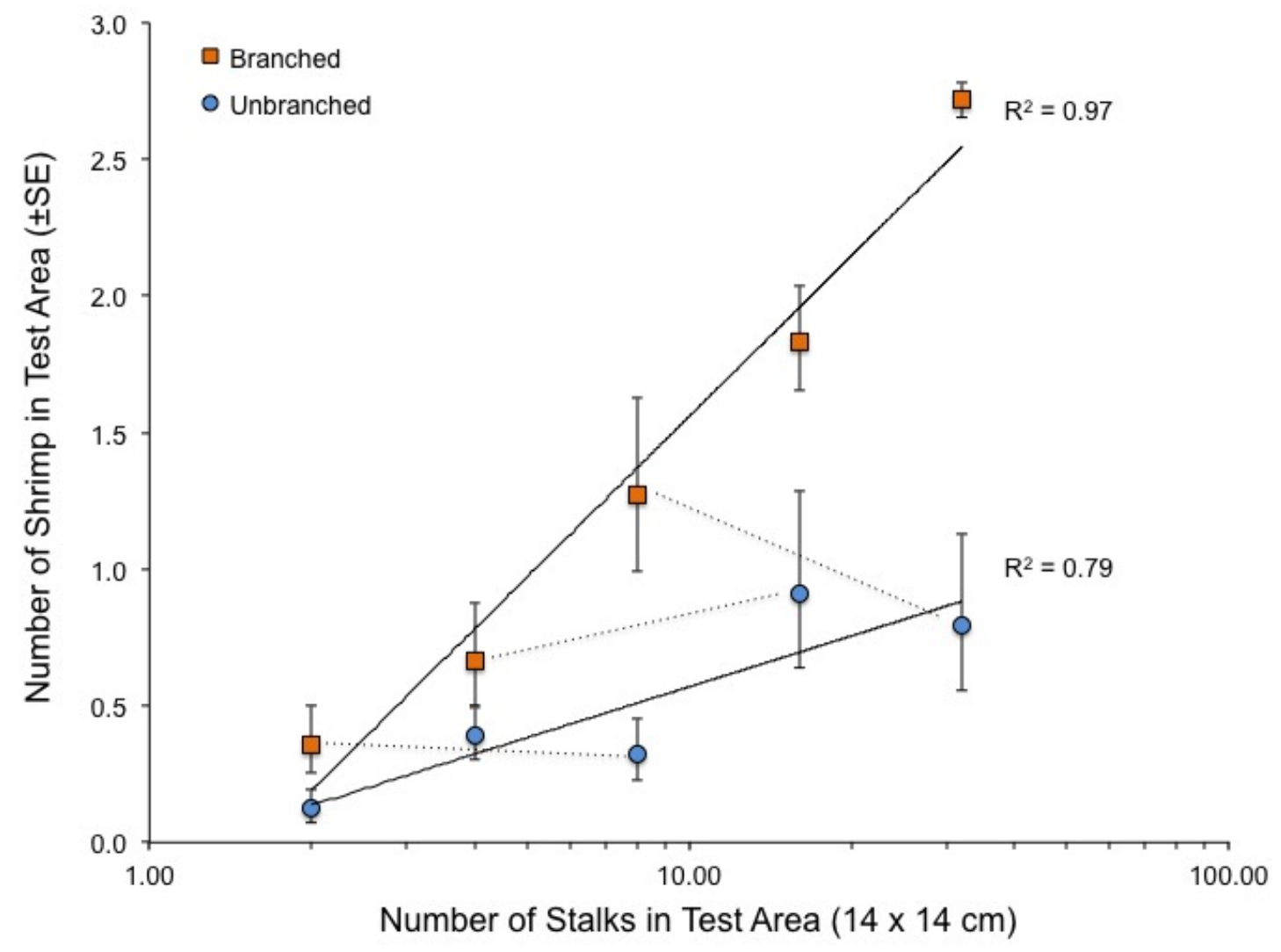


Figure 5. Relationship between total stalk surface area and number of shrimp in the test area in tanks with a single array.

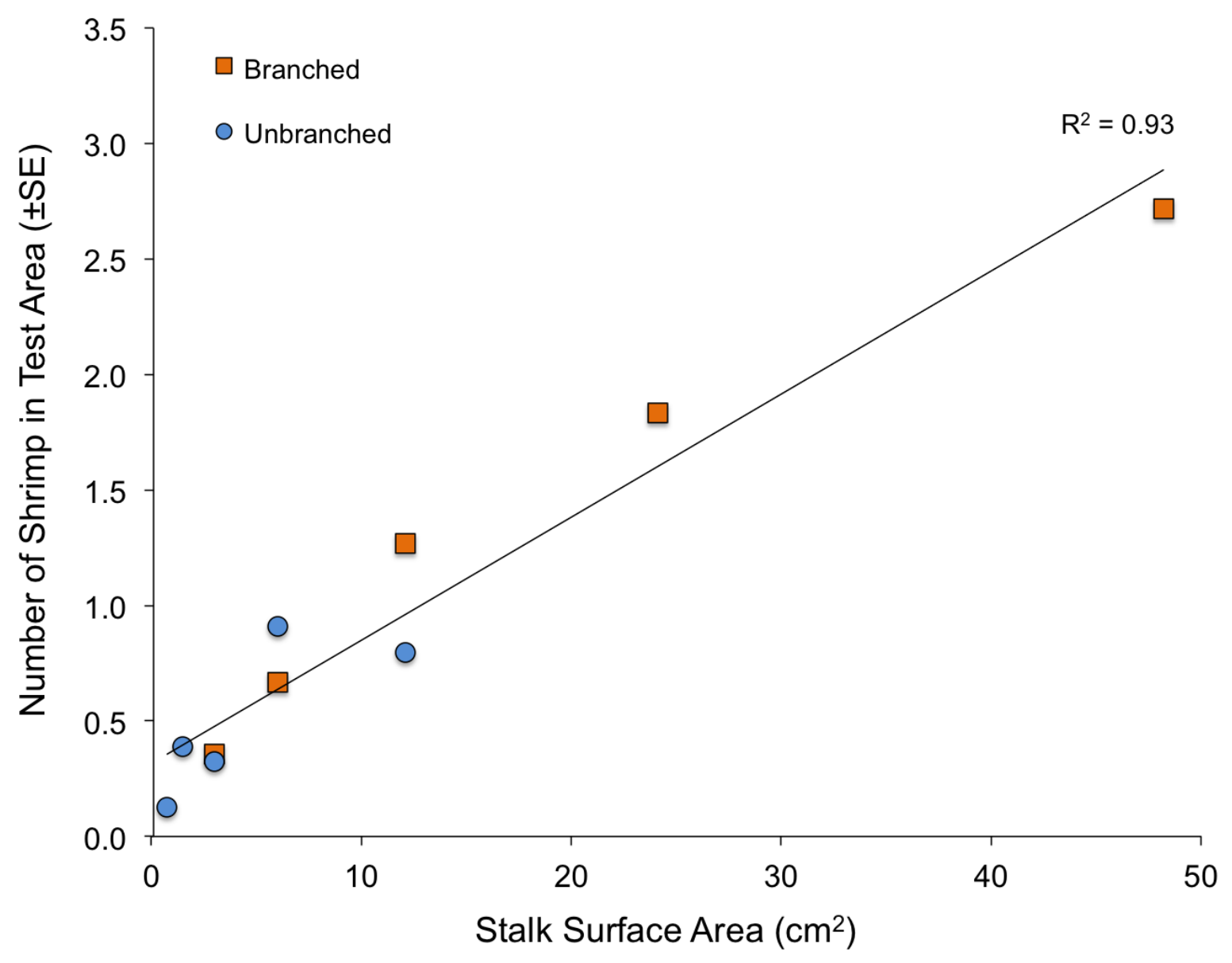


Figure 6. Relationship between the fractal dimension of the stalk arrays and toy treatments with and number of shrimp the test area.

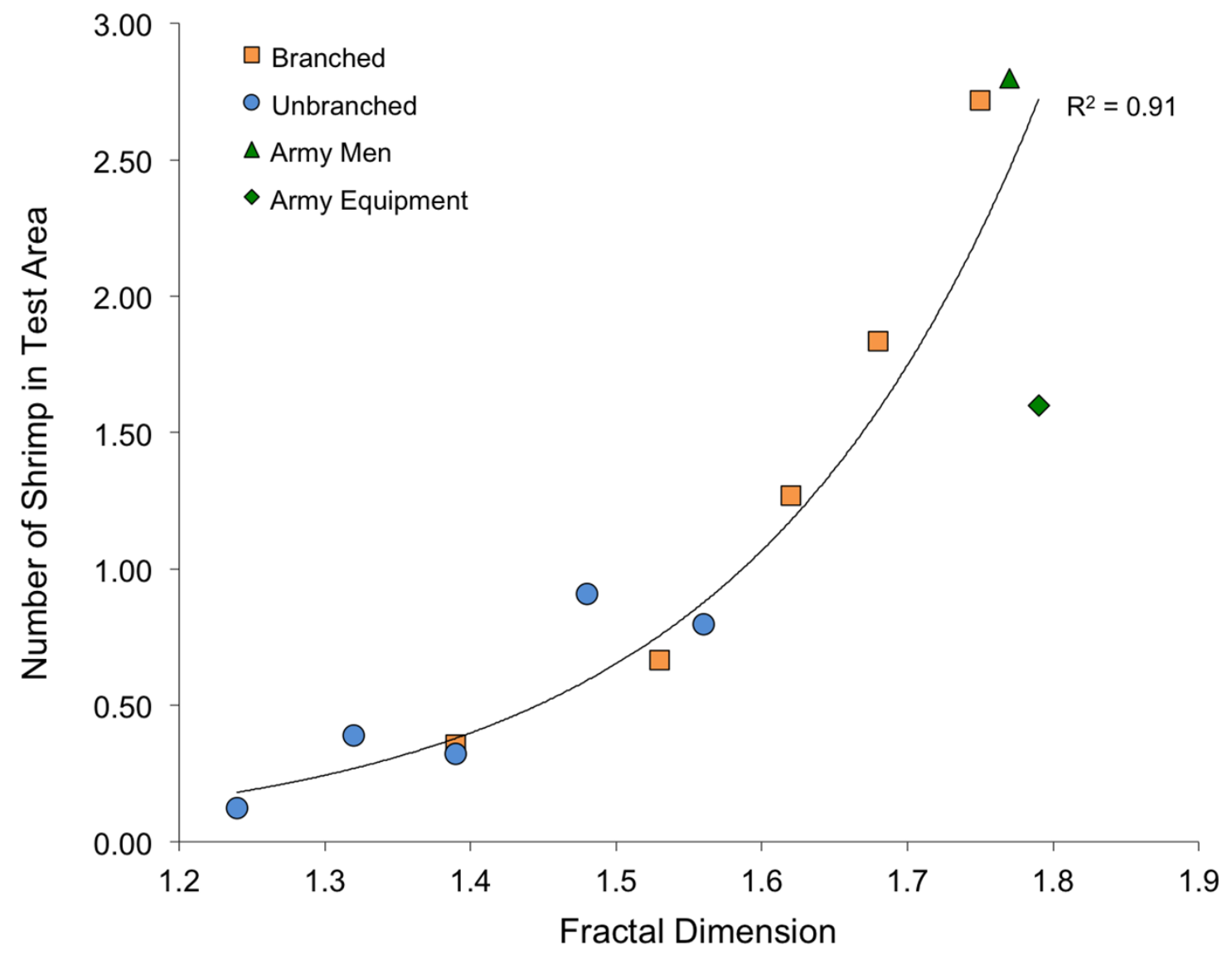

